\title{
Ten Misunderstandings about Maturity Models
}

\author{
Kim Normann Andersen \\ Department of Digitalization, Copenhagen Business \\ School, Denmark \\ andersen@cbs.dk \\ Tobias Mettler \\ Swiss Graduate School of Public Administration, \\ University of Lausanne \\ tobias.mettler@unil.ch
}

\author{
Jungwoo Lee \\ Center for Work Science, ICONS, Yonsei University, Seoul, \\ Korea \\ jlee@yonsei.ac.kr \\ M. Jae Moon \\ Department of Public Administration, Yonsei University, \\ Seoul, Korea \\ mjmoon@yonsei.ac.kr
}

\begin{abstract}
In this paper, we take the initial steps of re-formulating the research agenda on maturity models within the government context. Critiques on maturity models in government digitalization has been collected via a systematic review of academic literature. Synthesis of the articles $(n=47)$ has resulted in a list of ten objections and critique of maturity models. The author team of this paper has been heavily involved in pioneering and leading research on maturity models. Standing on the shoulders of this track-record, we have coinedf a possible response on how maturity models might still have an important role to play in theorizing about why, how and where government progresses in their use of digital technologies. Also, we argue that maturity models have an important role to play for practice in their navigation in a yet more multifaceted technological dependent government.
\end{abstract}

\section{CCS CONCEPTS}

- Social and professional topics $\rightarrow$ Computing / technology policy; • Applied computing $\rightarrow$ Computers in other domains; • Software and its engineering $\rightarrow$ Software creation and management.

\section{KEYWORDS}

Stage model, maturity model, electronic government, government digitalization

\section{ACM Reference Format:}

Kim Normann Andersen, Jungwoo Lee, Tobias Mettler, and M. Jae Moon. 2020. Ten Misunderstandings about Maturity Models. In The 21st Annual International Conference on Digital Government Research (dg.o '20), fune 15-19, 2020, Seoul, Republic of Korea. ACM, New York, NY, USA, 6 pages. https://doi.org/10.1145/3396956.3396980

Permission to make digital or hard copies of all or part of this work for personal or classroom use is granted without fee provided that copies are not made or distributed for profit or commercial advantage and that copies bear this notice and the full citation on the first page. Copyrights for components of this work owned by others than ACM must be honored. Abstracting with credit is permitted. To copy otherwise, or republish, to post on servers or to redistribute to lists, requires prior specific permission and/or a fee. Request permissions from permissions@acm.org.

dg.o '20, fune 15-19, 2020, Seoul, Republic of Korea

(c) 2020 Association for Computing Machinery.

ACM ISBN 978-1-4503-8791-0/20/06 . \$ \$15.00

https://doi.org/10.1145/3396956.3396980

\section{INTRODUCTION}

Modeling the developmental trajectory is instrumental for reconstituting how technologies have been developed and for conceptualizing how super-applications and provident services are transforming government through smart and mobile services [1]. Naturally, in the field of information systems, a plethora of these models have been developed over several decades by practitioners and researchers. These models come under different names, such as maturity models, stage models, benchmarking models, or adoption models. Especially, within the digital government area, a variety of maturity models have been developed as approaches to categorize for example the provision of online services with respect to organizational and technical dimensions. Among the most quoted e-government maturity models are the Layne \& Lee [2] and Andersen \& Henriksen [3] models. These maturity models have been employed as a basis in developing indices for assessing government digitalization across nations and used by international organizations.

In spite of proliferated adoption of maturity model in government digitalization, criticism is also abundant. Poor theoretical foundation, empirically not provable, too normatively absolute, and poorly designed basis for benchmarking are just a few examples of the criticism that maturity models are facing. In this regard, it has been pointed out that many predictions defined in maturity models about developments in e-government have failed to materialize in terms of actual practice by misleading governmental investment on information technologies.

This paper is a contribution towards correcting what we see as misunderstandings of maturity model in digital government research and practice. Common critique of maturity models includes questions such as "are the categories of a stage model well chosen? Do e-services evolve through such a series of stages? Is there a real advancement between the different stages? Should one always strive for higher stages? Are higher stages inherently better than lower stages? Is a stage model a proper yardstick for evaluation and benchmarking?" [4].

Despite ongoing disputes and rejections of the components and underlying logics of maturity models [5]-[8], IT capability maturity models $[9,10]$ are frequently part of most cap stone courses and there have been more than 30 papers published in the information systems senior scholar's basket of eight journals that had maturity models as key focus. Yet, according to Poeppelbuss et al. [11], there is a lack of ". . .development and usage of theoretically sound maturity models in practice". Such scarcity of theoretical questioning 
and the empirical monolithic research culture might be due to the unwillingness among researchers of different persuasions to change the deeply entrenched meanings of their terms.

The objective of this paper is to address misunderstandings as well as prospects of maturity models especially in terms of government digitalization. The paper aims to embrace the discussion of maturity models by addressing misunderstandings in view of common critiques and suggest possible directions for where and how the IS community can contribute to development and adequate use of maturity models in research and practice. We have focused our paper on maturity models within the public sector sphere. Although the research and findings are particularly relevant to the public sector field, we believe the critique and the forward suggestions we identify in this paper are relevant for other areas of the IS-field.

While the dynamics of computing can be more visible, be more glamorous, and possibly take longer leap frogs forward in the private sector, the government scene of IT-use has been shifting as well. Yet, we are short of knowledge of how organizations mature using newer generations of technologies. While managers in government during the 1970 s were equally uncertain about the nature of changes and how to respond to use of "office" technologies [12], the uncertainty of technologies 50 years later encompass a much broader plethora of technologies (cloud computing, Internet of Things, social media, AI, sensors, and data analytics) and an extended portfolio of users (citizens, companies, and politicians as well as computing fanatics). Our key propositions it that the IS research attention needs to be refocused on the new reality of government and discuss whether the critique and advantages of maturity models still makes sense. We argue in this conceptual paper that a major part of the critique of maturity models rely on somewhat misconceived premises as for accurate prediction of future and precise forecasting of technological development, and that the recent advantages in methodologies will make several of the reservations and concerns rather obsolete, leading to insightful use of maturity frameworks.

\section{MISUNDERSTANDINGS AND COUNTERPOINTS}

A recent literature review lists as many as 69 maturity models in use in practice [13]. While popular or at the minimum frequently brought to the table and referenced among practice, Röglinger et al. [14] question whether the high quantity of maturity model literature translates into high quality in practice. The critique is that maturity models and implicit maturity disguised as rankings make general statements about maturity that is difficult to translate into action at strategic, tactical, and operational level of government.

In the IS-community, there has been attempts to engage in how and who should use the models by, for example, focusing on IT integration issues. In our view, the work by Kim and Grant [15] translate straight forward into the CIOs practice. Also, the UN egovernment surveys published by-annually and being prepared by the UN University in Portugal, is quite explicit on the intended users: "....intended for policy makers, government officials, academia, civil society, private sector and other practitioners and experts in the areas of public administration, e-government, and ICTs for development" [16].
The author team of this paper has been involved in developing some of the most cited maturity models and have frequently been involved in discussions on shortcomings of maturity models. The author team from Asia and Europe have held online and physical meetings outlining the list of misunderstandings based on the discussions and critique we have had on our own papers and in academic discussion of these.

Critiques on maturity models in public sectors are collected via selective review process of academic and practical literature. 42 articles are selected from a research database. Each article was carefully read through identifying issues raised concerning objections and critiques about the maturity model. Collected critiques are classified and clustered into 10 misunderstandings. For these 10 misunderstandings, clarifications and suggestions are made by way of citing practical cases with in-depth analyses.

In Table 1 we have summarized what we view as misunderstandings and our argumentation why each of the ten arguments are misleading and jeopardize the possible contribution of maturity models to aid practice and move the research agenda forward.

Within the government area, the critique of maturity models has been quite fierce (e.g., $[17,18])$. One of the most important points of criticism is the fact that existing maturity models often lack a theoretical basis or empirical evidence to "proof" the significance and accuracy of prediction [22]. However, the purpose of a maturity model is not to provide absolute truth, but possibly to provide a useful instrument to practitioners in comprehending and dealing with the difficult task of digital transformation. In this sense, the development and evaluation of maturity models should not necessarily follow a positivistic approach, but rather a design-oriented paradigm [23] rooted in the basic principles of the sciences of the artificial [24], iteratively following incremental search processes for mapping the problem space with the solution space [25]-[28].

In a design-oriented paradigm, the maturity model is defined in the solution space. As shown in Figure 1, the stages of a maturity model defined in the solution space correspond to progressive definitions of insecurity and uncertainty in the problem space. Translated to the concept of maturity models, the solution space represents the diffusion and performance of a particular technology while the problem space represents reality with uncertainty and insecurity concerning the use of technology [29]. By means of many minor product or process improvements, technological solutions mature over time [30] and extend their outreach (or diffusion) to practice [31]. This is contrasted by the problem space, which in the case of maturity models frequently culminates in technology adoption decisions. A high insecurity in practice exists, when technology is in an emerging stage, respectively when there are only a handful observable implementations on which to base the decision whether to adopt or not to invest in a technology, as graphically presented in Figure 1

Accordingly, maturity models are most useful when the level of insecurity in practice is highest, respectively when technology has not yet reached a dominant design and consequently is in an emerging or progressive stage of evolution. However, this typically comes along with a situation when technological and organizational developments are most uncertain as the empirical case base for studying successful implementations is practically inexistent 
Table 1: Overview of misunderstandings and how to embrace the maturity models.

Misunderstanding
I. Maturity models are intended to be prescriptive tools, but there is no
explicit concept of who and how the models should be used [6]
Benchmarking, if they are poorly designed, it is risking distorting
government policies as countries may chase the benchmark rather
than looking at real needs and levels [17]
There is no empirical proof of the stages of growth. The stages are
constructive out of researchers' imagination and blue air approaches
[18]
The maturity models are not part of a wider theoretical set of research.
Hence, the models cannot be used for explaining maturity, at best it
can be applied for categorizing and descriptive statistics [18]
There is a misconceived linearity in the model. This is reflected in the
numbering of the stages and the visualization of the stages [6]

The unit of analysis is often very blurry. Since there is no explicit statement of whether analysis is at individual or collective level, the value of the maturity models is at best zero

Measurement of progress is often done through proxies or indicators. Most of the digital use, such as e-mailing and social media, are not measured [17]

"Maturity" in maturity models is absolute, not relative

Focus on internal and institutional benefits (integration etc.) and not citizens benefits

The methodological approach is deductive driven. Hence, the landscape of maturity research does not generate knowledge of multiple paths to maturity
Responses

The maturity models are not supposed to be instrumental in use. They can be a supportive tool and/or part of an enactment process [3]

There are different perceptions about what "maturity" means. The maturity of IT is a relative and fluid concept, not comparable with the maturity of a biological unit (e.g. an apple) where we can clearly measure "age" or "fruit sugar levels" There is evidence that provision of e-services and use of e-services is growing. The models rarely have a time dimension but research suggests that the uptake is a long-term process [19]. The slow uptake does not make the stages wrong Maturity models are, in general, not explanatory. There are emerging studies that link delivery of e-services to explanatory variables [20]

In many maturity models there is an implicit assumed linearity. However, there are models that work with spiral, evolutionary growth patterns. Also, there are models that work with identifying different path to maturing [21]

There are several models that state the unit of analysis (e.g., city government, school, health care facility) and the phenomena addressed (e.g., smart city, smart governance, smart work, smart grid)

Many of the empirical assessments of maturity models use secondary data. It is true that many of these measures base on website use and on top often use self-reported estimates. It is rarely they analyze log-files etc. However, there are examples of estimates through first hand-empirical data and also social media data [21]

Maturity levels are defined at absolute levels, not as a relative and dynamic concept. This raises also the question what and why is at level $1,2,3,4, \mathrm{n}$ ?

It is true that most e-government models are focused on government internal value, but there are models that argue and suggest levels of maturity for public value

There is a "growing" number of methodological advances, such as the SET method [21] (only few pioneers might use it). In this stage, recommended improvement activities are daringly highly speculative. Ungrounded conceptualizations of technology applications are defined and experimented. However, these kinds of speculations are still useful as they shed some light into a dark tunnel of insecurity and ignorance concerning the future development. They may guide and orient the further development of technology as well as behavioral and social use of these technologies. As the use cases accumulate, insecurity decreases. At the inflection point at which technology becomes disruptive and dominant designs appear, the diffusion reaches majority and beyond majority.

This logic is in conflict with positivistic thinking that aims at building highly accurate prediction models from the beginning. In order to get to a reasonable sample size for testing statistical models, researchers require lots of observable cases. However, if the adoption of a certain technology, process, or skillset is common sense, the developed model might not be of much use for practice as most organizations already underwent digital transformation.

Early research on conceptualizing maturity of technological entities have frequently used the analogy of stages [9] or ladders [32] which can gradually be climbed in order to reach perfection. Particularly the work on the Capability Maturity Model (CMM) has shaped the understanding of many scholars to comprehend maturity as linear process that can explicitly be defined, managed, measured, and controlled [33]. Accordingly, many of today's maturity models concentrate on and overemphasize the role of processes $[13,14]$, while disregarding other possible ways and possibilities of conceptualizing maturity, such as measuring skillsets of people 

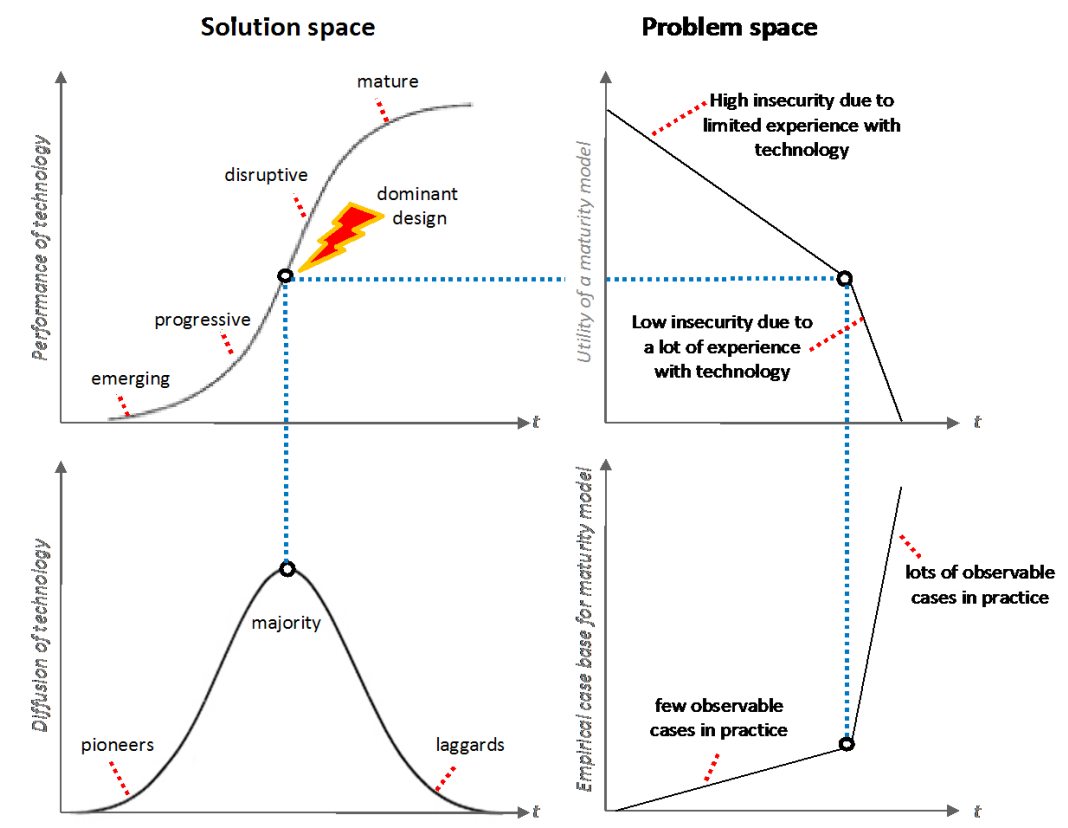

Figure 1: Relationship between technological evolution and utility of maturity models

or affordances of technology [34]. There is no need or rule that maturity models have to coercively adopt a process perspective.

In addition, the idea that maturity models develop in a linear way towards a final stage needs rethinking. Again, different from biological entities, which evolutionary process cannot be repressed (at the most, accelerated or decelerated), it is possible for technological entities to dynamically move backwards and forwards in terms of maturity as technology artifacts are malleable with creators intentions, as recent research shown [35]. Novel, more theoretical approaches for developing maturity models take this issue into account $[21,36]$. In this sense, there exist maturity models that are more dynamic in nature and with a working hypothesis of maturity beyond linear processes.

The unit of analysis of the maturity models refers to the basic entity that is investigated in the study including individuals, groups, organizations, systems, activities, etc. As the studies of e-government have different research subjects including public agencies, municipal governments [37, 38], and nations [39], the unit of analysis of maturity models also varies. In fact, the unit of analysis is not supposed to be fixed but is determined by the basic entity that a study is to focus on. For example, one might focus on the evolution and advancement of e-government at the municipal governments then the unit of analysis is municipal government while the national government should be the unit of analysis if a study aims to investigate the development of e-government at the national level.

One of the key objections towards maturity models is the assumed implicit assumption of evolutionary progress in the demonstration of a specific ability or in the accomplishment of a target from an initial to a desired or normally occurring end state [23].
However, different from a biological entity which stage of maturity can clearly be determined (e.g. by measuring fructose level, absorbance of chlorophyll), technology continuously evolves and in seldom cases reaches a stage of ultimate perfection. This is because the properties (or features) of technology relate to people's subjective goals and perceptions [40]; or in other words, a technological entity (or artifact) consists of a material part, which is independent of its use and the context in which it is used, and a social part relative to a person's perception and, hence, dependent on individual experience, knowledge, culture, or ability to perceive [41, 42].

Translated to the concept of maturity models, we should therefore start to comprehend maturity as a relative and dynamic concept with regard to both context and time. It is the result of a continuous and ongoing process of adaptation to a changing landscape of economic, socio-cultural, politico-legal, and technological beliefs, objectives, and conditions [43]. Therefore, what is "mature" today must not necessarily be "mature" tomorrow [35]; or what works in one context, must not necessarily work in another [44]. In this sense, the criticism towards maturity models that they cannot assure a positive outcome or "one true way" seems to be misplaced [45]. If a maturity model makes sense or is useful, lies in the eye of the beholder and point in time of usage.

Also, the UN e-government survey writes about the assessment of how digitalized government are in the UN member countries: "...the assessment rates the e-government performance of countries relative to one another, as opposed to being an absolute measurement. It recognizes that each country should decide upon the level and extent of its e-government initiatives in keeping with its own national development priorities and achieving the Sustainable Development Goals” [16]. Several empirical studies have been 
published on the digital maturity of municipalities [38] and cities [46]. These empirical studies include back-office applications of ICT and front-office applications which aims to provide public services and interact with citizens. E-government has been distinguished from computerization in government which began as a mean of improving processing, storage and management of information. Initially, e-government includes both internal applications of ICT for administrative efficiency and institutional benefits, and outward applications of ICTs for various operations and functions including G2C (government to citizens), G2B (government to business), and G2G (government to government) [47]. Later, the one-way outward conceptualization of e-government is being challenged by improved interactive capabilities of technologies and evolving citizen and stakeholder expectations for improvement of the interaction, collaboration, and coordination, which often is considered as e-governance [48].

\section{POLARIZING THE DEBATE ON MATURITY MODELS AND THE NEXT STEPS}

In this paper we have presented what we see as misunderstandings of maturity models - misunderstandings that potential can limit the engagement of scholars in bringing e-government forward. Being aware that opposing view will argue that each of the arguments are valid objections against maturity models, this paper is likely to be regarded as ignoring the weak spots of maturity models. For example, in discussions with academic about our ten propositions we have been challenged with regards to our position with regards to what kind of concept maturity is when we discuss it. Thus, among the forward issues to address is whether maturity exists as a separate entity-object, is it a property of something, or is it a path to something else? Also, there is substantial work to be done on how to judge the prescriptive value of maturity models in use.

Maturity models themselves need to be taken as evolutionary reference models for future research and practice. Coming waves of new integrative technology demands us to come up with new shape of governance despite unchanging underlying principles of bureaucracy. Devising new ways of governance without conceptualizing maturity models might be a nautical journey without orientation. It becomes even more true in the coming age of malleable and integrative information and communication technologies. A discipline without prospective maturity, no matter how absurd, is much less effective than the one with multiple competing maturity models. Further evolution of public administration and related research including currently ongoing government digitalization may only be strengthened by good and abundant discussions on maturity models embedded in our efforts.

Embracing the maturity models in the forward research agenda on e-government has severe methodological, axiological, and epistemological challenges that need to be resolved with the advance of technologies. Along the methodological dimension, there is a clear need to have more studies and more solid case studies on the use of maturity models. Citing Thomas Kuhn, Flyvbjerg [49] formulated this as "a discipline without a large number of thoroughly executed case studies is a discipline without systematic production of exemplars, and that a discipline without exemplars is an ineffective one" [49]. Along the axiological dimension the e-government community needs to re-iterate the balance between rigor and relevance, possible by expanding on both dimensions. Finally, there is major room for more research along the epistemological dimensions and more explicit investigations on interpretivist versus positivism, subjectivist versus objectivist, and emic versus etic dimensions. For maturity models to have more academic soundness we encourage maturity model research to incorporate these dimensions and through this soundness help the community to mature in its approach to maturity models.

\section{REFERENCES}

[1] Lemke, F., Taveter, K., Erlenheim, R., Pappel, I., Draheim, D. and Janssen, M. Stage Models for Moving from E-Government to Smart Government. Springer, Cham, 2020.

[2] Layne, K. and Lee, J. Developing Fully Functional E-Governemnt: A Four-Stage Model. Government Information Quarterly,18, 2 (2001), 122-136.

[3] Andersen, K. and Henriksen, H. E-Government Maturity Models: Extension of the Layne and Lee Model. Government Information Quarterly, 23, 2 (2006), 236-248.

[4] Goldkuhl, G. and Persson, A. From E-Ladder to E-Diamond - Re-Conceptualising Models for Public E-Services. In Proceedings of the 14th European Conference on Information Systems (Göteborg, Sweden, 2006)

[5] Galliers, R. D. and Sutherland, A. R. Information Systems Management and Strategy Formulation: The 'Stages of Growth' Model Revisted. Information Systems Journal, 1, 2 (1991), 89-114.

[6] King, J. L. and Kraemer, K. L. Evolution and Organizational Information Systems: An Assessment of Nolan's Stage Model. Communications of the ACM 27, 5 (1984), 466-475.

[7] Bannister, F. and Connolly, R. The Future Isn't What It Used to Be: Forecasting the Impact of Ict on the Public Sphere. Government Information Quarterly, 37, 1 (2020), 101410.

[8] Wastell, D. and Sewards, A. An Information Systems Profile of the Uk Manufacturing Sector. Journal of Information Technology, 10, 3 (1995), 179-189.

[9] Nolan, R. L. Managing the Computer Resource: A Stage Hypothesis. Communications of the ACM, 16, 7 (1973), 399-405.

[10] Humphrey, W. S. Characterizing the Software Process: A Maturity Framework. IEEE Software, 5, 2 (1988), 73-79.

[11] Poeppelbuss, J., Niehaves, B., Simons, A. and Becker, J. Maturity Models in Information Systems Research: Literature Search and Analysis. Communications of the Association for Information Systems, 29, 1 (2011), 505-532.

[12] Danziger, J. N. Computers and the Frustrated Chief Executive. MIS Quarterly 1, 1 (1977), 44-53.

[13] Van Looy, A., Poels, G. and Snoeck, M. Evaluating Business Process Maturity Models. Journal of the Association for Information Systems, 18, 6 (2017), 461-486.

[14] Röglinger, M., Pöppelbuß, J. and Becker, J. Maturity Models in Business Process Management. Business Process Management Journal, 18, 2 (2012), 328-346.

[15] Kim, D.-Y. and Grant, G. E-Government Maturity Model Using the Capability Maturity Model Integration. Journal of Systems and Information Technology, 12, 3 (2010), 230-244

[16] United Nations. United Nations E-Government Survey 2018 Gearing EGovernment to Support Transformation Towards Sustainable and Resilient Societies. New York, 2018

[17] Bannister, F. The Curse of the Benchmark: An Assessment of the Validity and Value of E-Government Comparisons. International Review of Administrative Sciences, 73, 2 (2007), 171-188.

[18] Coursey, D. and Norris, D. F. Models of E-Government: Are They Correct? An Empirical Assessment. Public Administration Review, 68, 3 (2008), 523-536.

[19] Rooks, G., Matzat, U. and Sadowski, B. An Empirical Test of Stage Models of EGovernment Development: Evidence from Dutch Municipalities. The Information Society, 33, 4 (2017), 215-225.

[20] Budding, T., Faber, B. and Gradus, R. Assessing Electronic Service Delivery in Municipalities: Determinants and Financial Consequences of E-Government Implementation. Local Government Studies, 44, 5 (2018), 697-718.

[21] Lasrado, L., Vatrapu, R. and Andersen, K. N. A Set Theoretical Approach to Maturity Models: Guidelines and Demonstration. In Proceedings of the 37th International Conference on Information Systems (Dublin, Ireland, 2016).

[22] Biberoglu, E. and Haddad, H. A Survey of Industrial Experiences with CMM and the Teaching of CMM Practices. Journal of Computing Sciences in Colleges, 18, 2 (2002), 143-152.

[23] Mettler, T. Maturity Assessment Models: A Design Science Research Approach. International Journal of Society Systems Science, 3, 1/2 (2011), 81-98.

[24] Simon, H. A. The Sciences of the Artificial. MIT Press, Cambridge, MA, 1996.

[25] Nunamaker, J. F., Chen, M. and Purdin, T. D. M. Systems Development in Information Systems Research. Journal of Management Information Systems, 7, 3 (1991), 89-106. 
[26] Peffers, K., Tuunanen, T., Rothenberger, M. A. and Chatterjee, S. A Design Science Research Methodology for Information Systems Research. Journal of Management Information Systems, 24, 3 (2008), 45-77.

[27] Walls, J. H., Widmeyer, G. R. and El Sawy, O. A. Building an Information Systems Design Theory for Vigilant Eis. Information Systems Research, 3, 1 (1992), 36-59.

[28] Hevner, A. R., March, S. T., Park, J. and Ram, S. Design Science in Information Systems Research. MIS Quarterly, 28, 1 (2004), 75-105.

[29] Mettler, T. Thinking in Terms of Design Decisions When Developing Maturity Models. International Journal of Strategic Decision Sciences, 1, 4 (2010), 76-87.

[30] Utterback, J. M. and Abernathy, W. J. A Dynamic Model of Process and Product Innovation. Omega, 3, 6 (1975), 639-656.

[31] Rogers, E. M. Diffusion of Innovations. Free Press, New York, 1962.

[32] Mogilensky, J. and Stipe, D. Applying Reusability to Software Process Definition In Proceedings of the Conference on Tri-Ada '89 (Pittsburgh, 1989).

[33] Paulk, M. C., Curtis, B., Chrissis, M. B. and Weber, C. V. Capability Maturity Model, Version 1.1. IEEE Software, 10, 4 (July 1993), 18-27.

[34] Bach, J. The Immaturity of the Cmm. American Programmer, 7 (1994), 13-13.

[35] Mettler, T. and Pinto, R. Evolutionary Paths and Influencing Factors Towards Digital Maturity: An Analysis of the Status Quo in Swiss Hospitals. Technological Forecasting and Social Change, 133 (2018), 104-117.

[36] Lahrmann, G., Marx, F., Mettler, T., Winter, R. and Wortmann, F. Inductive Design of Maturity Models: Applying the Rasch Algorithm for Design Science Research. In Proceedings of the 6th International Conference on Design Science Research in Information Systems and Technology (Milwaukee, USA, 2011).

[37] Moon, M. J. The Evolution of E-Government among Municipalities: Rhetoric or Reality? . Public Administration Review, 62, 4 (2002), 424-433.

[38] Norris, D. F. and Moon, M. J. Advancing E-Government at the Grassroots: Tortoise or Hare? Public Administration Review, 65, 1 (2005), 64-75.

[39] Moon, M. J. and Welch, E. Managing E-Government. In Handbook of Public Administration, Jossey-Bass, San Francisco, 2015.
[40] Leonardi, P. M. When Flexible Routines Meet Flexible Technologies: Affordance, Constraint, and the Imbrication of Human and Material Agencies. MIS Quarterly, 35, 1 (2011), 147-176.

[41] Treem, J. W. and Leonardi, P. M. Social Media Use in Organizations: Exploring the Affordances of Visibility, Editability, Persistence, and Association. In Communication Yearbook, Routledge, New York, 2013

[42] Davern, M., Shaft, T. and Te'eni, D. Cognition Matters: Enduring Questions in Cognitive Is Research. Journal of the Association for Information Systems, 13, 4 (2012), 273-314.

[43] Kane, G. C., Palmer, D., Nguyen Phillips, A., Kiron, D. and Buckley, N. Achieving Digital Maturity: Adapting Your Company to a Changing World. MIT Sloan Management Review and Deloitte University Press, Boston, 2017.

[44] Mettler, T. and Rohner, P. Situational Maturity Models as Instrumental Artifacts for Organizational Design. In Proceedings of 4th International Conference on Design Science Research in Information Systems and Technology (Philadelphia, USA, 2009).

[45] Fraser, P., Moultrie, J. and Gregory, M. The Use of Maturity Models/Grids as a Tool in Assessing Product Development Capability. In Proceedings of the 2002 IEEE International Engineering Management Conference (Cambridge, UK, 2002).

[46] Fietkiewicz, K. J., Mainka, A. and Stock, W. G. Egovernment in Cities of the Knowledge Society. An Empirical Investigation of Smart Cities' Governmental Websites. Government Information Quarterly, 34, 1 (2017), 75-83.

[47] Norris, D. F. E-Government... Not E-Governance... Not E-Democracy Not Now! Not Ever? In Proceedings of the 4th International Conference on Theory and Practice of Electronic Governance (Beijing, China, 2010).

[48] Moon, M. J., Lee, J. and Roh, C.-Y. The Evolution of Internal It Applications and E-Government Studies in Public Administration: Research Themes and Methods. Administration and Society, 46, 3 (2014), 3-36.

[49] Flyvbjerg, B. Five Misunderstandings About Case-Study Research. Qualitative Inquiry, 12, 2 (2006), 219-245. 